\title{
The types of mechanical and thermal stresses on the first stage rotor blade of a turbine
}

Tipos de tensiones mecánica y térmica en la primera etapa de la pala del rotor de una turbina

Author:

Rafid M. Hannun ${ }^{(1)}$

Hazim I. Radhi (2)

Noura A.Essi (3)

\section{SCIENTIFIC RESEARCH}

How to cite this paper:

Hannun R, Radhi H., Essi N., The Types of Mechanical and Thermal Stresses on the First Stage Rotor Blade of a Turbine. Innovaciencia. 2019; 7 (1): 1-11.

http://dx.doi.org/10.15649/2346075X.513

Reception date:

Received: 20 May 2019

Accepted: 21 September 2019

Published: 25 October 2019

Keywords:

Simulation; X20Cr13; Steam turbine; ANSYS.

\begin{abstract}
Introduction: In this paper, the simulation of first stage of low pressure turbine for Nasiriya Power Plant was done to study the aerodynamic characteristic of steam along stage at load $70 \mathrm{MW}$, also the two types of mechanical stresses on the first stage rotor blade were studied in this paper. Materials and Methods:The material of blade was X20Cr13 stainless steel grade 1.4021. The first type of mechanical stresses which due to the steam pressure on the blade was analyzed. The seconds types of mechanical stresses that the centrifugal stresses on the blade. The AutoCAD software code was used for modeling the turbine stage, the dimensions and operational conditions were obtained practically from Nasiriya power plant and ANSYS (15.0) software was used to make simulate the turbine. Results and Discussion: The results showed that maximum steam velocity occurred at trailing edge of stationary blades and leading edge of rotating blades, also the maximum stresses occurred at the leading edge and trailing edge of root blade, the stresses due to the effect of centrifugal force is larger than the stresses due the pressure force. Conclusions: The maximum deformation occurred at tip of blade and minimum deformation depicted at root of blade.
\end{abstract}

Prof. Dr. Mechanical Eng., College of Eng., University of Thi -Qar, rafid.alsaleh@gmail.com, ORCID 0000-0002-4061-5080

Assist. Prof. Dr. Mechanical Eng., College of Eng., University of Thi -Qar, hazimesmael@gmail.com.

MSc. Mechanical Eng. Dept., College of Eng, University of Thi -Qar, alyassrinoura@gmail.com. 


\section{INTRODUCTION}

Steam turbine is the most significant prime mover for converting the heat energy that steam emits to mechanical energy in turn electrical power ${ }^{(1)}$. Steam turbine is utilized in different kinds of power generations such as coal-fired power generations, electrical generators, nuclear power generations, gas turbine

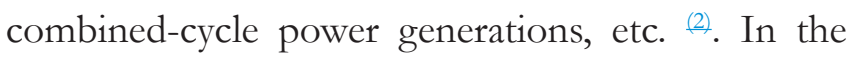
steam turbine, the high-pressure, high-temperature steam from nozzle flows in an annular space to the stationary blades and is directed tangentially against the rotating blade. In the stator or nozzle, the fluid is accelerated while the static pressure decreases and the tangential velocity of the fluid is increased in the direction of rotation. While the rotor decreases the tangential velocity in the direction of rotation, the fluid on the rotor blades exerts tangential forces, and a resulting torque is produced on the output shaft $\frac{(3)}{-}$.

The blades of turbines could be considered as the turbine's heart, due to the fact that they're the main elements converting the working fluid energy to kinetic energy. The turbine's effectiveness and reliability are dependent on the suitable blade design. Thus, it is very important for engineers that are involved in the turbine design to overview the necessity and basic engineering aspects of the steam turbine blades, which is a multi-disciplinary job. It is involved with the disciplines of thermo-dynamic, aero-dynamic, mechanic and material science ${ }^{(4)}$. There are various types of blades that may be classified according to their implementations to the three turbine modules which are: high-pressure turbine, intermediate-pressure turbine and low-pressure turbine. The first two types, high-pressure and intermediate-pressure, are identifies by high temperatures and the fact of them containing small blades which have to maintain small centrifuge forces ${ }^{(2)}$. Low-pressure turbine blades, designed for the extraction of the final energy remainder from the passing steam flow, are rather large scale rotating air-foils because of the considerable centrifuge forces that are experienced throughout ordinary operations. Statistics show that low-pressure turbine blades are usually more susceptible to failure than those of the high-pressure turbine and intermediate pressure turbine ${ }^{(4)}$.

The forces acting on a rotating turbine blade are composed of $\stackrel{(5)}{ }$ :

1. Centrifugal force due to rotation.

2. Bending force due to the fluid pressure and change of momentum.

3. Bending force due to centrifugal action, resulting from that the centroids of all sections do not lie along a single radial line.

Ali and Sahib (2007) ${ }^{(6)}$ studied the thermal and mechanical stresses on the gas turbine blade in Baghdad. ANSYS 5.4 software was used for analysis the stresses. The effect of thickness, temperature and speed of rotation on the stresses and deformation are studied in their study. They observed that the increasing of the blade thickness leads to decrease in the stresses and deformation where thin blades give greater stresses and deformations than the thick blades. In addition, the stresses and deformations were increased when the speed of rotation increased, also, the increases of the blade temperature leads to increase in the stresses and deformations.

Oscar et al. (2013) ${ }^{(7)}$ calculated the temperature fields and thermal stresses in a micro gas turbine during at the start-up transient cycle. Fluent and ANSYS codes were used to calculate the temperature fields and thermal stresses, respectively. The results showed the highest thermal stresses were located on the nozzle trailing edge and on the rotor leading edge, respectively. In addition, the highest temperature value and the highest thermal stress value reached were under the yield strength of the material.

Rogowski and Pawlicki (2017) investigated the flow of steam past a last stage of the high-pressure 
part of the TK120 steam turbine by using computational fluid dynamics (CFD). The simulations were performed by using the unsteady compressible $\mathrm{Na}$ vier-Stokes equations. They display the distributions of instantaneous flow parameters around turbine blades as well as instantaneous aerodynamic blade loads are presented. The distributions of velocity and static pressure were presented around the rotor disc blade at four different instants. They concluded from their results that the maximum static pressure occurs at the leading edge of stationary and decrease gradually until reaches minimum static pressure at the trailing edge of rotor blades. Also, they observed that the minimum steam velocity at the leading edge of stationary blades and increases gradually until reaches maximum value at trailing edge of stationary blades and leading edge of rotor blades.

In this work. The aerodynamics characteristic for steam along first stage of low-pressure of Nasiriya Power Plant steam turbine is obtained and studying the mechanical stresses on the first stage blade for Nasiriya power plant steam turbine.

\section{MATERIALS AND METHOD}

\section{MODEL DESCRIPTION}

The aerodynamic flow through the first stage of the low pressure turbine for Nasiriya power plant at load $70 \mathrm{MW}$ was simulated in this paper. The steam expands from 0.6 bar as a total pressure, the steam temperature as $473 \mathrm{~K}$, the rotation speed of the rotor is $3000 \mathrm{rpm}$ and $226.5 \mathrm{Ton} / \mathrm{hr}$ as the steam flow rate ${ }^{(9)}$. In addition, the stress distribution of single rotor blade for turbine stage was calculated, due to the complex shape of the blade, the variation of thickness along the blade and the curvature angle of blade where measurements were taken of the real blade at the station and then the blade was drawn by AutoCAD indicated in figure1. and use ANSYS 15.0 software to calculate stress distribution of blade.

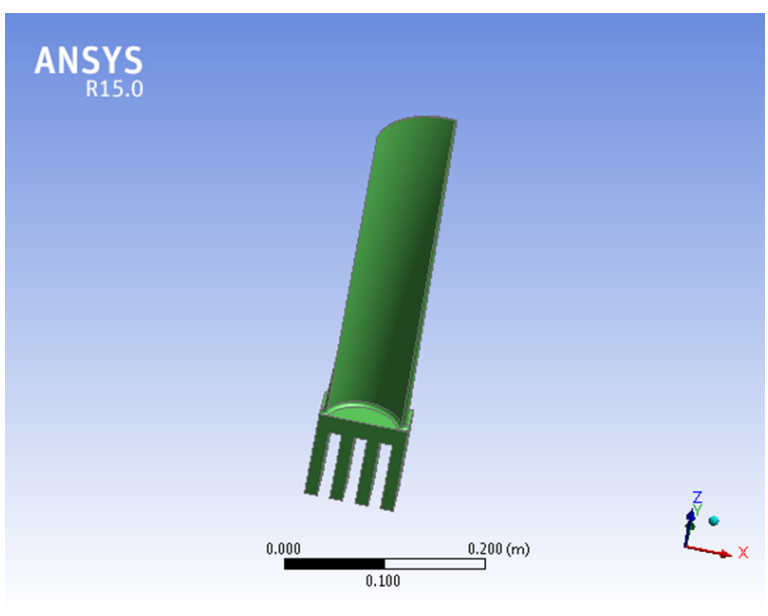

Figure 1. First rotor blade.

The boundary condition was applied on the blade is $341 \mathrm{rad} / \mathrm{sec}$ as the rotational speed and the steam pressure on the blade was $512 \mathrm{~Pa}$.

\section{MATHEMATICAL MODEL}

The governing equation of three dimensional, steady state is used to analyse the flow of the turbine stage as in the following equation ${ }^{(10)}$ :

Continuity equation

$\frac{\partial}{\partial x i}\left(\rho \cup_{\mathrm{i}}\right)=0$

Momentum equation

$\frac{\partial}{\partial x_{i}}\left(\rho U_{i} U_{j}\right)=-\frac{\partial P}{\partial x_{i}}+\frac{\partial}{\partial x_{j}}\left[\mu\left(\frac{\partial U_{i}}{\partial x_{j}}+\frac{\partial U_{j}}{\partial x i}\right)-\rho u_{\imath} u_{J}\right]+F_{i}$

Energy equation

$\frac{\partial}{\partial x_{i}}\left(c_{p} \rho u_{j} T\right)=\frac{\partial}{\partial x_{j}}\left[k \frac{\partial T}{\partial x_{j}}-\overline{\rho u_{j}} t\right]$

\section{TURBULENT MODEL}

There are two model equations for turbulent one for kinetic energy $\mathrm{k}$ and other for dissipation rate, the model transport equation for $\mathrm{k}$ is derived from the exact equation, while the model transports equation for $\varepsilon$ was obtained by using the physical analysis. The standard model uses the following transport equa- 
tions for $\mathrm{k}$ and $\varepsilon^{(11)}$.

For turbulent kinetic energy $(\mathrm{k})$ :

$\frac{\partial}{\partial x_{j}}\left(\rho U_{j} k\right)=\frac{\partial}{\partial x_{j}}\left[\left(\mu+\frac{\mu_{t}}{\sigma_{k}}\right) \frac{\partial k}{\partial x_{j}}\right]+G_{k}-\rho \varepsilon$

For energy dissipation rate $(\mathcal{E})$ :

$\frac{\partial}{\partial x_{i}}\left(\rho U_{j} \varepsilon\right)=\frac{\partial}{\partial x_{j}}\left[\left(\mu+\frac{\mu_{t}}{\sigma_{\epsilon}}\right) \frac{\partial \varepsilon}{\partial x_{j}}\right]+C_{1 \epsilon} \frac{\varepsilon}{k} G_{k}-\rho C_{2 \epsilon} \frac{\varepsilon^{2}}{k}$

where:

$\mathrm{G}_{\mathrm{K}}$ : Production term of turbulence

$G_{k}=-\rho u_{\imath} u_{J}\left(\frac{\partial u_{i}}{\partial x_{j}}\right)$

$\mu_{t}=\rho C_{\mu} \frac{k^{2}}{\varepsilon}$

Where the parameters can be found from table $1^{(12)}$ :

Table 1. The parameters of $\mathrm{k}-\varepsilon$ model equations .

\begin{tabular}{cc}
\hline The parameter & Value \\
\hline$\sigma_{\varepsilon}$ & 1.3 \\
$\sigma_{\mathrm{k}}$ & 1.0 \\
$\mathrm{C}_{\mu}$ & 0.09 \\
$\mathrm{C}_{2 \varepsilon}$ & 1.92 \\
$\mathrm{C}_{1 \varepsilon}$ & 1.44 \\
\hline
\end{tabular}

\section{I4. COMPLICATED STRESSES}

The normal stress $\sigma$ and shear stress $\tau$ acting on an inclined planes due to the direct loads are $\frac{(13,14)}{\text { : }}$

$$
\begin{aligned}
& \sigma=\sigma_{y} \sin ^{2} \phi \\
& \tau=-\frac{1}{2} \sigma_{y} \sin ^{2} \phi
\end{aligned}
$$

The stresses acting on an inclined planes are :

$\sigma_{\varnothing}=\frac{1}{2}\left(\sigma_{x}+\sigma_{y}\right)+\frac{1}{2}\left(\sigma_{x}-\sigma_{y}\right) \cos 2 \emptyset+\tau_{x y} \sin 2 \emptyset(10)$

$$
\tau_{\varnothing}=\frac{1}{2}\left(\sigma_{x}-\sigma_{y}\right) \sin 2 \varnothing-\tau_{x y} \cos 2 \emptyset
$$

Where:

$\sigma_{0}$ : normal stress on the inclined planes.

$\tau_{\emptyset}$ : shear stress on the inclined planes.

The principle stresses (maximum and minimum stresses) on inclined planes are:

$\sigma_{1}=\frac{1}{2}\left(\sigma_{x}+\sigma_{y}\right)+\frac{1}{2} \sqrt{\left[\left(\sigma_{x}-\sigma_{y}\right)^{2}+4 \tau_{x y}{ }^{2}\right]}$

$\sigma_{1}=\frac{1}{2}\left(\sigma_{\mathrm{x}}+\sigma_{\mathrm{y}}\right)-\frac{1}{2} \sqrt{\left[\left(\sigma_{\mathrm{x}}-\sigma_{\mathrm{y}}\right)^{2}+4 \tau_{\mathrm{xy}}{ }^{2}\right]}$

The maximum shear stress is :

$\sigma_{\max }=\frac{1}{2} \sqrt{\left[\left(\sigma_{x}-\sigma_{y}\right)^{2}+4 \tau_{x y}{ }^{2}\right]}=\frac{1}{2}\left(\sigma_{1}-\sigma_{2}\right)$

The analytical equations of the forces acting on the turbine blades in the following ${ }^{(5)}$ :

Steam force $=\mathrm{ms} \times$ velocity change

$\mathrm{F}_{\mathrm{st}}=\dot{\mathrm{m}}_{\mathrm{s}}\left(V_{w 1}+V_{w 2}\right)$

The general equation for centrifugal force is :

$F_{c f}=m r \omega^{2}$

When taken an infinitesimal element $(\mathrm{dz})$ is seprated in section $\mathrm{Z}$ as shown in figure 2. The centrifugal force developed by this element during disc will be (6):

$\mathrm{df}_{\mathrm{cf}}=\mathrm{dm} \cdot \omega^{2}\left(\mathrm{R}_{\mathrm{r}}+\mathrm{z}\right)$

$\mathrm{dm}=\rho \cdot \mathrm{A}(\mathrm{z}) \mathrm{dz}$

$\mathrm{df}_{\mathrm{cf}}=\rho \cdot \omega^{2} \cdot A(\mathrm{z}) \cdot\left(\mathrm{R}_{\mathrm{r}}+\mathrm{Z}\right) \mathrm{dz}$

$F_{c f}(x)=\int_{x}^{l b} \rho \cdot \omega^{2} \cdot A(z) \cdot\left(R_{r}+Z\right) d z$ 
Consider the blade as cantilever beam with variable cross-section and fixed at the root so that the cross section variable according to the equation:

$$
\begin{aligned}
& \left(\frac{\mathrm{A}(\mathrm{z})}{\mathrm{Ar}}\right)^{\mathrm{lb}}=\left(\frac{\mathrm{At}}{\mathrm{Ar}}\right)^{\mathrm{z}} \\
& \frac{\mathrm{A}(\mathrm{z})}{\mathrm{Ar}}=\left(\frac{\mathrm{At}}{\mathrm{Ar}}\right)^{\mathrm{z} / \mathrm{lb}} \\
& \mathrm{A}(\mathrm{z})=\operatorname{Ar} \cdot\left(\frac{\mathrm{At}}{\mathrm{Ar}}\right)^{\mathrm{z} / \mathrm{lb}} \\
& F_{c f}=\rho \cdot \omega^{2} \int_{\mathrm{x}}^{\mathrm{lb}}\left[\operatorname{Ar} \cdot\left(\frac{\mathrm{At}}{\mathrm{Ar}}\right)^{\frac{\mathrm{z}}{\mathrm{lb}}}\right] \cdot\left(\mathrm{R}_{\mathrm{r}}+\mathrm{Z}\right) \mathrm{dz} \\
& \mathrm{F}_{\mathrm{cf}}=\rho \cdot \omega^{2}\left[\mathrm{R}_{\mathrm{r}} \int_{\mathrm{x}}^{\mathrm{lb}} \operatorname{Ar} \cdot\left(\frac{\mathrm{At}}{\mathrm{Ar}}\right)^{\frac{\mathrm{z}}{\mathrm{lb}}} \cdot \mathrm{dz}+\int_{\mathrm{x}}^{\mathrm{lb}} \operatorname{Ar} \cdot \mathrm{z}\left(\frac{\mathrm{At}}{\mathrm{Ar}}\right)^{\frac{\mathrm{z}}{\mathrm{lb}}} \cdot \mathrm{dz}\right]
\end{aligned}
$$

after solving and finding the integral equation "(26)" it gets the centrifugal force at any point along the length of blade as in equation "(27)" :

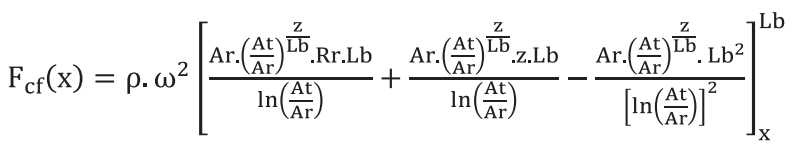

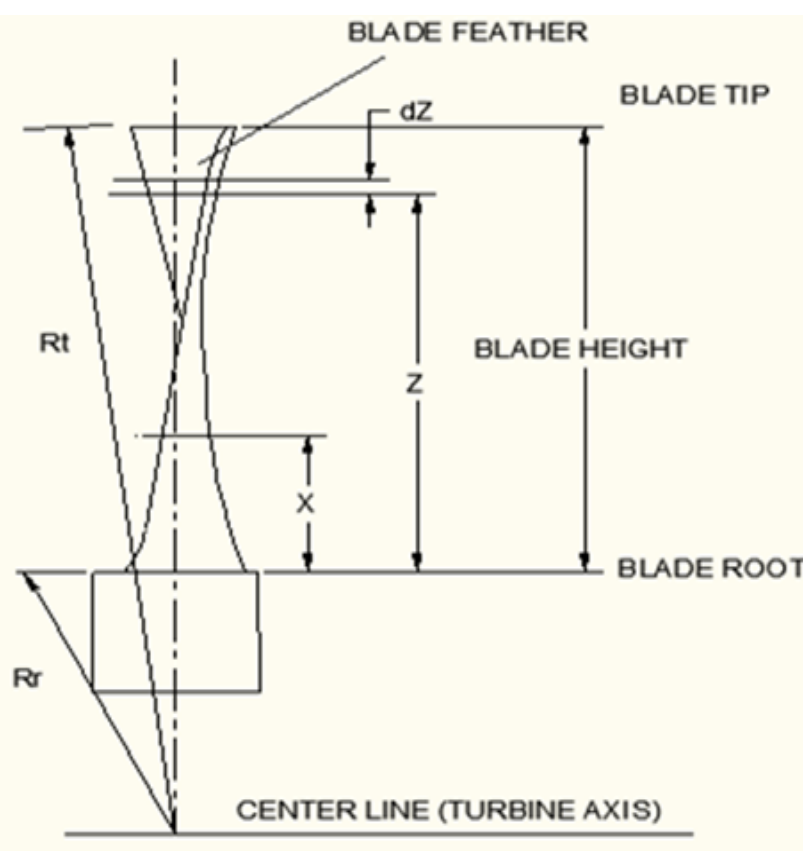

Figure 2. Calculation of the centrifugal force (5).

\section{RESULTS AND DISCUSSION}

Figure 3. shows the contour of steam velocity distribution along the axial distance of the first stage turbine. The steam velocity inlet to first stage of turbine is $36.148 \mathrm{~m} / \mathrm{s}$ and inlet temperature is $473 \mathrm{~K}$. From this figure its can be notice that the steam velocity is increased gradually along the stationary blades until reaches the maximum value at trailing edge of stationary blades. The reason that the decreasing of cross section area at outlet from stationary blades leads to increase velocity, also in the stationary blades converts of thermal energy for steam to kinetic energy. In addition, it can be observed that the steam enters to rotating parts at maximum velocity and decreasing gradually to the minimum value at outlet from stage. The reason that the rotating blades observed the kinetic energy therefore decreasing velocity of steam.

Figure 4. illustrates the variation the static pressure for steam with axial distance of stage at one third of maximum load where steam enters to first stage at $60000 \mathrm{~Pa}$ and steam velocity is $36.186 \mathrm{~m} / \mathrm{s}$. It can be observed the pressure decreases gradually along the stationary blades due to decrease the area of flow at outlet from stationary blades, that causes decrease pressure and increase velocity of steam. Where the stationary blades directs the steam at low pressure and high velocity to rotating blades. From this figure it can be also seen the steam inlet to rotating parts at minimum pressure and the pressure almost will be constant along the moving blades.

Figure 5. presented the distribution of steam temperature with axial distance of stage at steam velocity $36.186 \mathrm{~m} / \mathrm{s}$ and steam temperature $473 \mathrm{~K}$. From this figure it can be seen that temperature decreases along stage until reaches to minimum value $443 \mathrm{~K}$ at outlet from stage. The reason of decreasing the steam temperature the steam is expanded and loss of its internal energy along stage, according to laws of 
thermodynamics state that when steam expands, its internal energy is decreased and therefore the temperature is drops.

Figure 6. shows the contour of distribution for Von Misses stresses through the first stage rotor blade. The pressure applied on the blade is $512 \mathrm{~Pa}$. It can be observed from this figure the construction of stresses and maximum stresses occurs at the leading edge of root blade, the value is $3.141 \mathrm{MPa}$. In addition, it can be notice the minimum stress occurs at the tip of blade, where this value is $0.3498 \mathrm{MPa}$. The reason that the bending moment is large at the root of the blade, then it decreased when mover towards of the end of blade, therefore the stresses resulting from steam force are high at the root of the blade because their value depends on the bending.

Figure 7 , indicates the variation of equivalent elastic strain on the first rotor blade, where the pressure is acting on the blade at this load is $512 \mathrm{~Pa}$. From this can be seen the maximum equivalent strain occurs at the leading edge of root blade and decreases gradually until reaches minimum value at the tip of blade. The values of maximum and minimum stain are $(0.0000158 \mathrm{a}, 0.000001762)$ respectively.

Figure 8. demonstrates the deformation variation on the first rotor blade at load $70 \mathrm{MW}$. From this figure can be seen the maximum deformation occurs at tip of blade and decrease gradually until reaches minimum value at the tip of blade. The maximum value for deformation is $0.4108 \mathrm{~m}$ and minimum value is $0.4585 \mathrm{~m}$.

Figure 9. shows the Von Mises stresses due to the effect of centrifugal force acting on the blade. It can be seen from this figure the concentration of stresses and the maximum stresses occurs at the leading edge and trailing edge near of the root blade. The value of maximum stresses is $51.346 \mathrm{MPa}$ and the stresses are reduced when move towards the upper end of blade until reaches to minimum stresses at the tip of blade is $5.705 \mathrm{MPa}$. The reason that the centrifugal force is as large as possible at the root and decreases as we move towards upper end of the blade. The centrifugal force is function to the length of the blade as shown in equation 27 . Where the centrifugal force is variable according to mass and length of the blade. In addition, the stresses results at centrifugal force larger than the stresses due to the steam pressure at all loads are studied.

Figure 10, indicates the distribution of equivalent elastic strain on the blade due to the effect of centrifugal force. From this figure can be observed the maximum strain occurs at the leading edge and trailing edge of the root blade, the value of maximum strain is 0.2613 . The strain is reduced when move towards the upper of blade until reaches to minimum strain at the tip of blade is 0.32446 . The reason is that the centrifugal force is as large as possible at the root and decreases as we move towards upper end of the blade.

Figure 11. displays the variation deformation on the blade due to the effect of centrifugal force. From this figure can be seen the deformation is variable along blade, also the maximum deformation occurs at the tip blade is $0.43081 \mathrm{~m}$ and decrease gradually until reaches to minimum deformation at the root of blade is $0.478567 \mathrm{~m}$.

Table 2, represents the results of maximum and minimum Von Mises stresses on the blade due to the steam pressure on the blade at load $70 \mathrm{MW}$ and the stresses due to the centrifugal force.

From the results of this table, we observe the rotational load has the greatest effect on the blade. Also the stresses due to rotational load are higher than stresses due to steam pressure. 

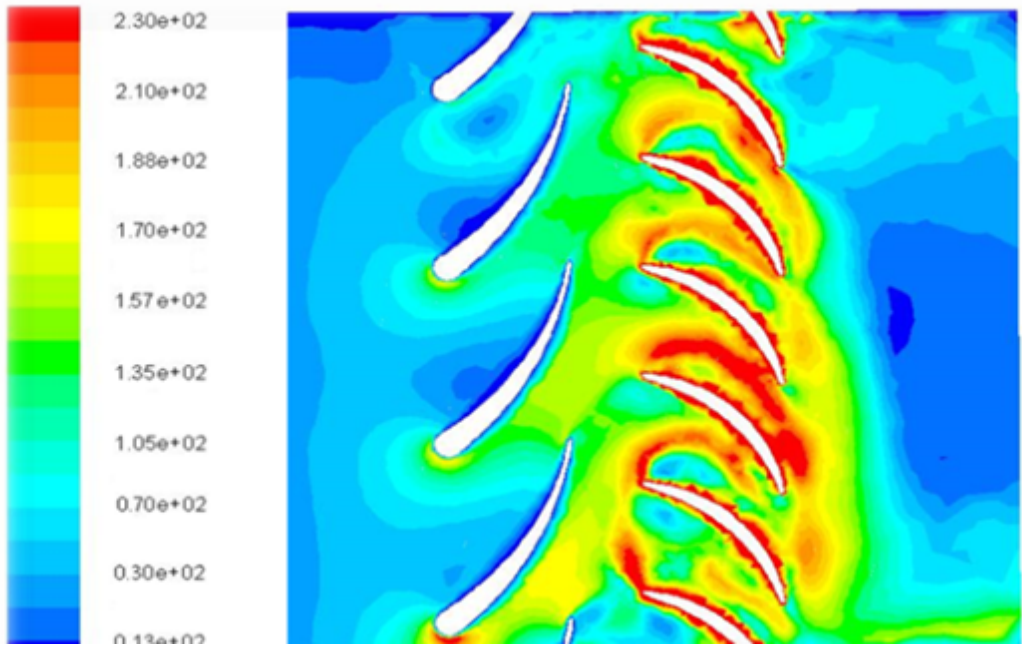

Figure 3. The contour of steam velocity distribution along the axial distance.

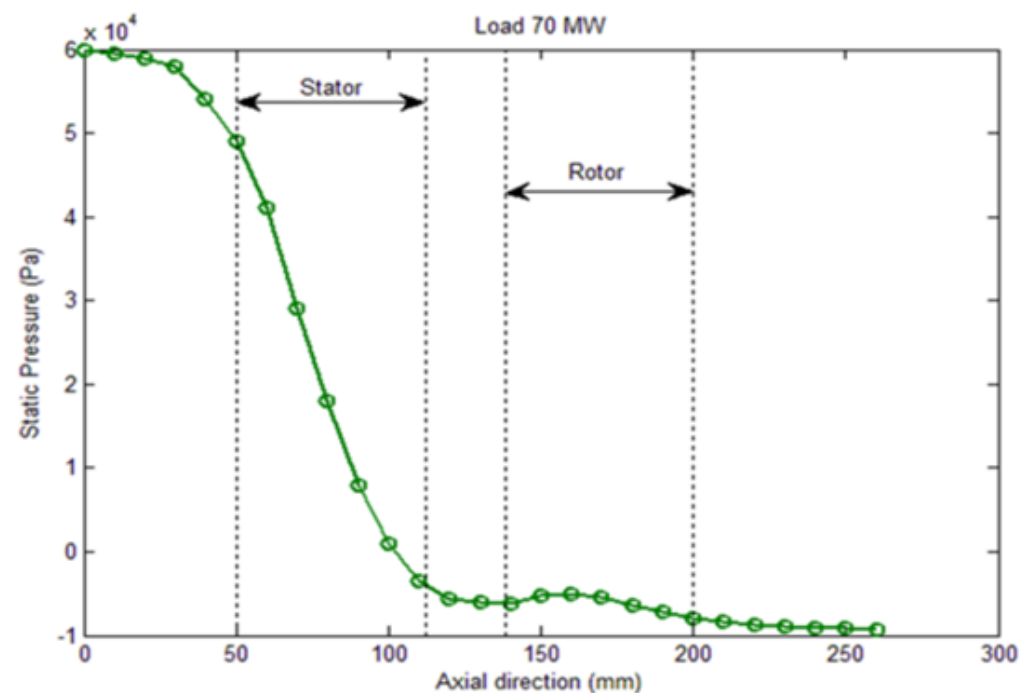

Figure 4. Distribution of static pressure along axial distance of stage.

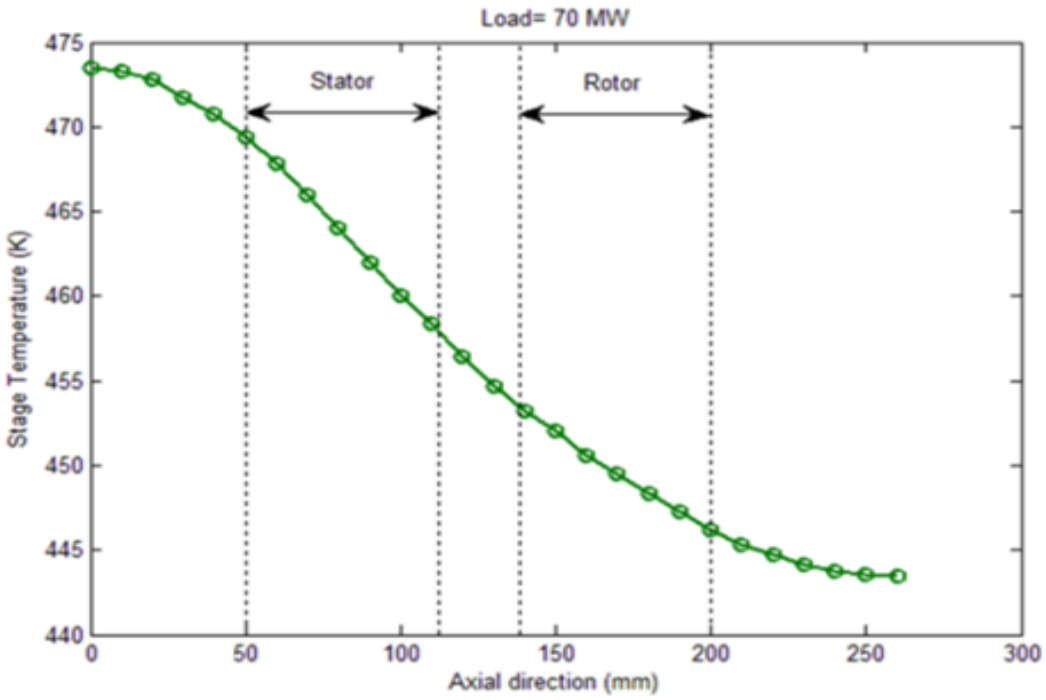

Figure 5. The variation of steam temperature along stage. 


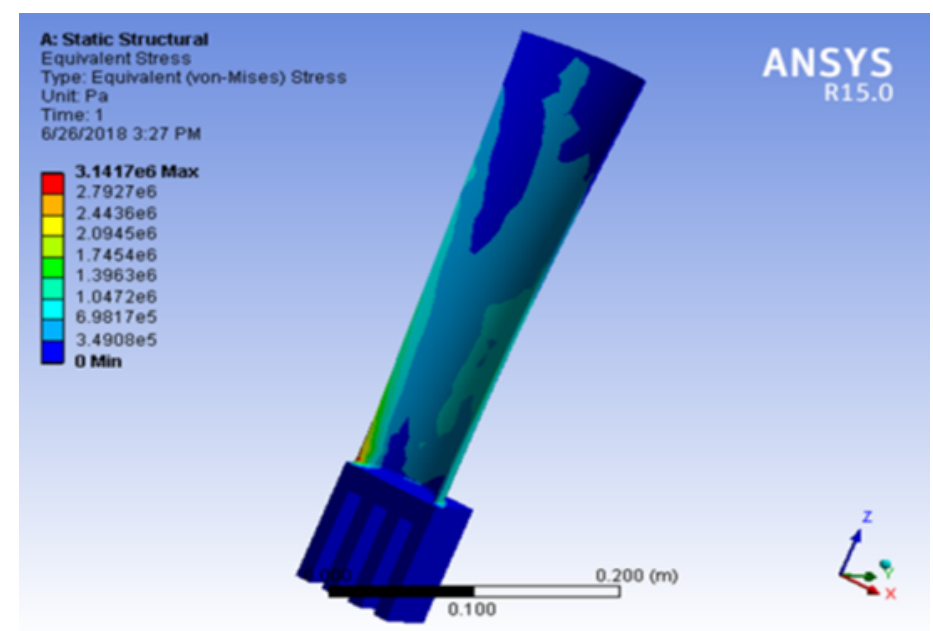

Figure 6. The equivalent Von Mises stress due to steam pressure.

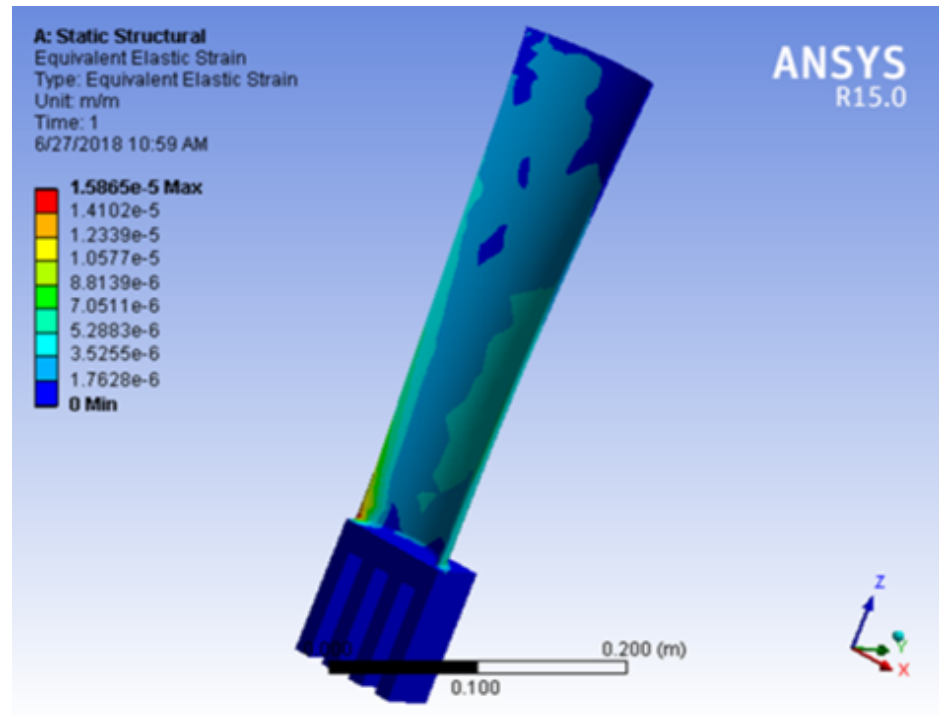

Figure 7. The equivalent Von Mises strain due to steam pressure.

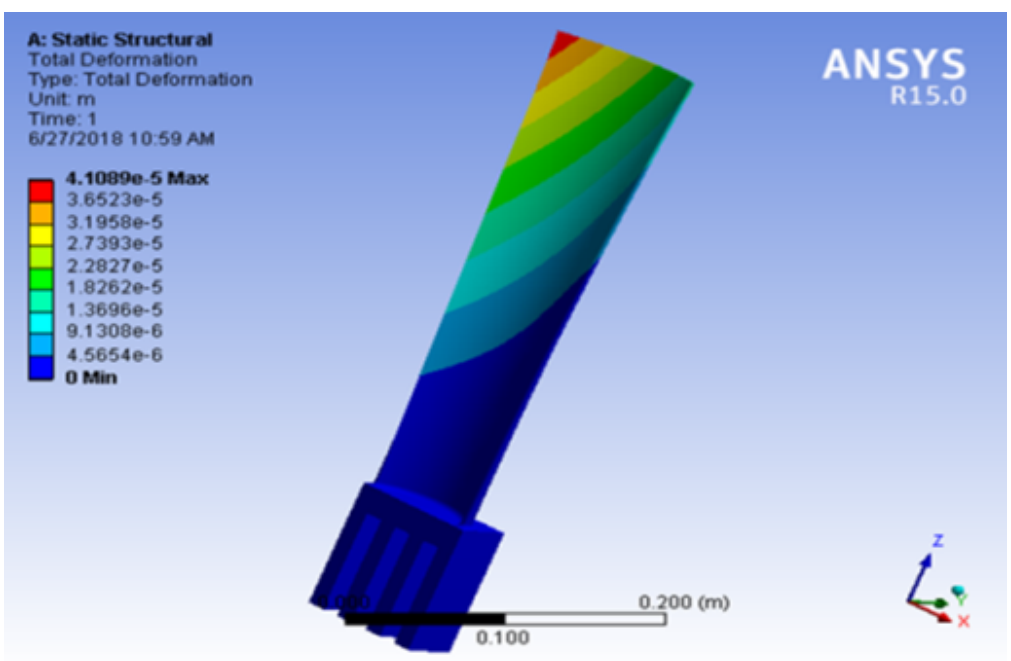

Figure 8. The total deformation due to steam pressure. 


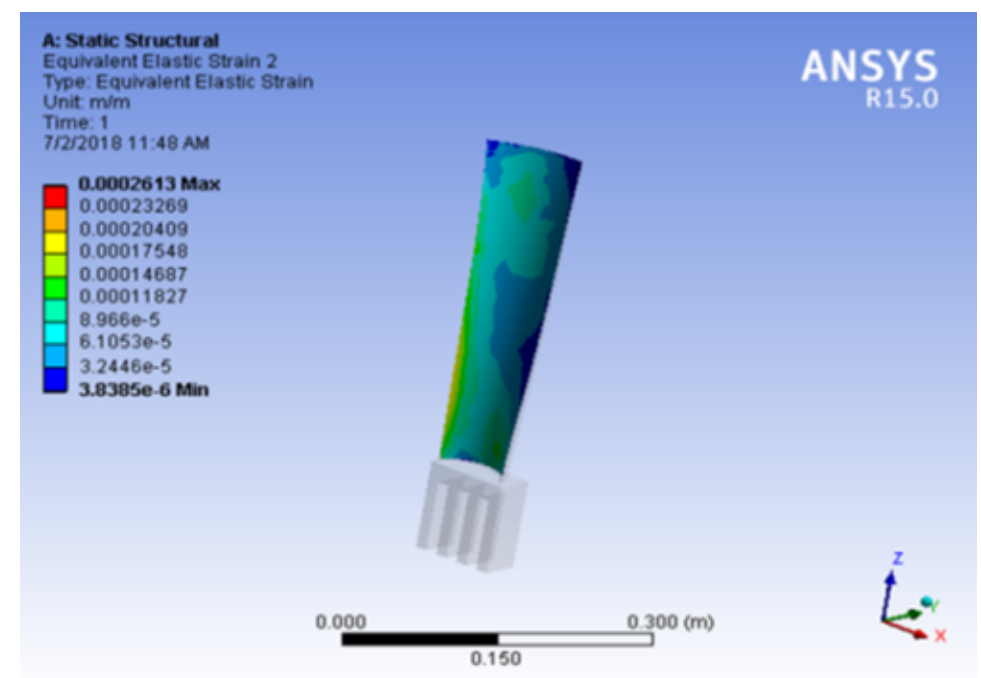

Figure 9. The equivalent Von Mises stress due to centrifugal force.

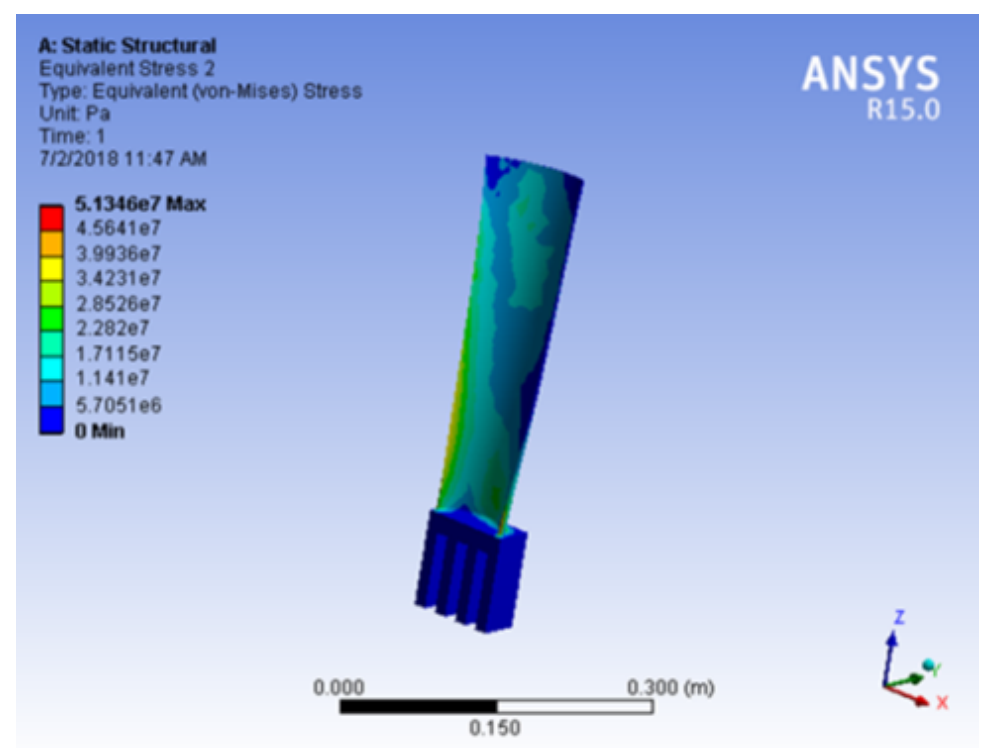

Figure 10. The equivalent Von Mises strain due to the centrifugal force.

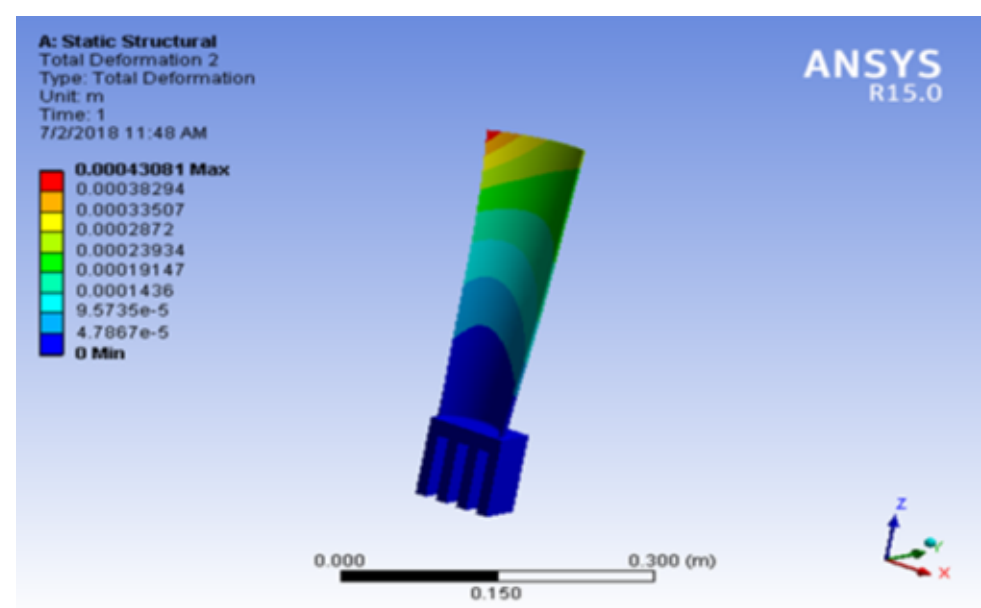

Figure 11. The total deformation due to the centrifugal force. 
Table 2. Results of Von Mises stresses on the blade at different loads.

Type of loads $\quad$ Maximum stresses $(\mathrm{MPa})$ Minimum stresses $(\mathrm{MPa})$

$\begin{array}{lll}\text { Pressure load at } 70 \mathrm{MW} & 3.1417 & 0.34908\end{array}$

Centrifugal load (341 rad/sec) $51.346 \quad 5.7051$

\section{CONCLUSIONS}

1. The maximum velocity occurred at the trailing edge of stationary blades and leading edge of rotating blades.

2. The minimum velocity occurs at the trailing edge of moving blades.

3. The steam temperature is decreased along stage and the minimum steam velocity occurred at the trailing edge of moving blades.

4. The static pressure was decreased gradually through the stationary blades until reaches minimum value at inlet to rotating blades.

5. The distribution of Von Mises stresses due to the pressure of steam was concentrated on the leading edge and trailing edge in the root of the blade.

6. The stresses generated on the blade due to centrifugal force was concentrated on the leading edge and trailing edge in the root of the blade

7. The stresses generated due to the centrifugal force was larger than the stresses generated due to pressure force.

\section{NOMENCLATURE}

$\rho$ : fluid density $\left(\mathrm{kg} / \mathrm{m}^{3}\right.$

$\mathrm{C}_{\mathrm{p}}$ : Specific heat at constant pressure $(\mathrm{J} / \mathrm{kg} \mathrm{K})$.

$\mathrm{T}=$ temperature $(\mathrm{K})$.

$\mathrm{K}=$ thermal conductivity $\left(\mathrm{W} \cdot \mathrm{m}^{-1} \cdot{ }^{\circ} \mathrm{C}^{-1}\right)$.

$\mathrm{V}_{\text {steam }}$ : velocity of steam in pipe $\left(\mathrm{m} \cdot \mathrm{s}^{-1}\right)$.

$G_{K}$ : the generation of turbulence kinetic energy due to the mean velocity gradients.

$\mathrm{C} \mu$ : constant in turbulent equation.

$\mu t$ t turbulent viscosity (N.s/m $\mathrm{m}^{2)}$.

$\sigma$ : normal stress (MPa)

$\tau$ : shear stress (MPa) $\sigma_{\varnothing}$ : normal stress on the inclined planes (MPa).

$\tau_{\varnothing}$ : shear stress on the inclined planes (MPa).

$\mathrm{F}_{\mathrm{cf}}$ : the centrifugal force $(\mathrm{N})$

At: cross section area of blade tip (

Ar: cross section area of blade root (

Rr: radius from shaft center at the blade root $(\mathrm{m})$

Lb: blade height $(\mathrm{m})$

$\rho_{\mathrm{m}}$ material density $\left(\mathrm{kg} / \mathrm{m}^{3}\right)$

\section{REFERENCES}

1. Rajput R. A text book of Thermal Engineering. Laxmi publication. First edition, 1993; 755- 880.

2. Heidari M and Amini K. Structural modification of a steam turbine blade," Materials Science and Engineering. 2017; 203(1).

https://doi.org/10.1088/1757-899X/203/1/012007

3. Mattingly J. Elements of gas turbine propulsion. Tata McGraw-Hill edition.1996.

4. Reddy A, et al. Analysis of Steam Turbines," International Refereed Journal of Engineering and Science. 2014; 3(2) :32-48.

5. Al-Taie A. Stress Evaluation of Low Pressure Steam Turbine Rotor Blade and Design of Reduced Stress Blade. Engineering and Technology Journal. 2008; 26 (2):169-179.

6. Ali, M and AL-sahib N. Effect of the Mechanical and Thermal Stresses of Rotating Blades. AlKhwarizmi Engineering Journal. 2007; 3(2): 3248.

7. Tenango O, et al. Numerical calculation of thermal stresses in a micro gas turbine. Memorials del xix congreso internacional annual dela somin, 2015. 
8. Rogowski K and Pawlicki, J. Numerical analysis of the steam flow past the turbine blade stage," Journal of Machine Engineering. 2017; 17(2): 102110.

9. Issa S. General Directorate of Electricity Production in Nasiriyah, "Nasiriyah Thermal Power Plant" Training on Turbine Operation K-210130.

10. Iacovides H, Kelemenis G. and Raisee M. Flow and heat transfer in straight cooling passages with inclined ribs on opposite walls: an experimental and computational study. Experimental Thermal and Fluid Science. 2003: 27(3): 283-294.

https://doi.org/10.1016/S0894-1777(02)00298-4

11. ANSYS FLUENT Theory Guide, Release 14.0, 2011

12. Launder B, and Spalding D. The Numerical Computation of Turbulent Flow. Computer Methods in Applied Mechanics and Engineering. 1974: 3(2): 269-289.

https://doi.org/10.1016/0045-7825(74)90029-2

13. Heran E. Mechanics of Materials 1: An Introduction to the Mechanics of Elastic and Plastic Deformation Solids and Structural Materials. Butterworth-Heine-mann, London. 1997

14. Tahir H. Mechanical Design of Moldboard Plow Bottom Throe Stresses Analysis and Performance Measurement. PhD Thesis, University of Mosul.2004. 